\title{
Time trends of cancer mortality among elderly in Italy, 1970-2008: an observational study
}

\author{
Ettore Bidolii ${ }^{*}$, Lucia Fratino ${ }^{2}$, Silvia Bruzzone ${ }^{3}$, Marilena Pappagallo ${ }^{3}$, Paolo De Paolii, Umberto Tirelli ${ }^{5}$ \\ and Diego Serraino ${ }^{1}$
}

\begin{abstract}
Background: The aging of the Italian population will unavoidably lead to a growing number of persons diagnosed and living with cancer. A comprehensive description of the burden of cancer mortality among Italian elderly (65-84 years of age) in the last four decades has not been carried out yet. Cancer mortality rates were used to describe time trends between 1970-2008.

Methods: Mortality counts, provided by the Italian National Institute of Statistics, were grouped according to data availability: in quinquennia from 1970-74 through 1995-99, and in 2000-03 and 2006-08 groups. Age-standardized rates (world population) were computed by calendar periods while annual percent changes (APCs) were computed for elderly and middle aged (35-64 years) people for the period 1995-2008.

Results: The number of cancer deaths in elderly nearly doubled between 1970-74 (31,400 deaths/year in men, and 24,000 in women) and 2006-08 (63,000 deaths/year in men, and 42,000 in women). Overall cancer mortality rates peaked during the quinquennia 1985-89 and 1990-94 (about 1,500/100,000 in men and 680 in women) and declined thereafter. Throughout 1995-2008 cancer mortality rates decreased by $-1.6 \% / y e a r$ in men and $-0.9 \% / y e a r$ in women. These decreases were mainly driven by cancers of the stomach, bladder, prostate, and lung (APC $=-3.3 \%$, $-2.7 \%,-2.5 \%,-2.2 \%$, respectively) in men, and by cancers of the stomach, bladder, and breast (APC $=-3.5 \%,-1.9 \%$, $-1.1 \%$, respectively) in women. Conversely, increases in mortality rates between 1995 and 2008 were recorded for lung cancer $(\mathrm{APC}=+0.6 \%)$ in women, cutaneous melanoma $(\mathrm{APC}=+1.7 \%)$ in men, and pancreatic cancer ( $\mathrm{APC}=+0.6 \%$ in men and $+0.9 \%$ in women).

Conclusions: Overall favorable trends in cancer mortality were observed among Italian elderly between 1995 and 2008. Early diagnosis, improved efficacy of anti-cancer treatments and management of comorbidities are the most likely explanations of these positive observations. However, enduring preventive interventions against the most common risk factor (e.g. cigarette smoking), early diagnosis, and access to care should be reconsidered and extended to match the reductions of cancer mortality recorded in the elderly with those in the middle aged.
\end{abstract}

Keywords: Cancer mortality, Time trends, Elderly, Italy

\section{Background}

It is well known that the incidence of most cancers increases approximately as the $4^{\text {th }}-5^{\text {th }}$ power of age. However, aging should not be considered an independent risk factor but a surrogate of prolonged carcinogen exposure [1-3]. In 2008, in Italy, nearly $60 \%$ of about 150,000 cancer deaths occurred in the 10.5 million

\footnotetext{
*Correspondence: bidolie@cro.it

${ }^{1}$ Unit of Epidemiology and Biostatistics, Centro di Riferimento Oncologico, IRCCS, via Franco Gallini 2, 33081 Aviano, PN, Italy

Full list of author information is available at the end of the article
}

elderly aged between 65 and 84 years. Elderly population is expected to increase by $11 \%$ in 2020 , and by $29 \%$ in 2030 [4], and this increase will unavoidably lead to a growing number of elderly people diagnosed and living with a neoplastic disease.

Mortality rates from some neoplasms steadily declined among the whole Italian population up to the last published update in 2007 [5,6]. Downward trends were mainly recorded for cancers of the stomach and intestines in both sexes, and in men only, for lung and other tobacco-related neoplasms. For some cancer types it is

\section{Biomed Central}

(C) 2012 Bidoli et al.; licensee BioMed Central Ltd. This is an Open Access article distributed under the terms of the Creative Commons Attribution License (http://creativecommons.org/licenses/by/2.0), which permits unrestricted use, distribution, and reproduction in any medium, provided the original work is properly cited. 
likely that the widespread implementation of early diagnosis programs (e.g. breast and prostate) and/or the introduction in the clinical practice of new treatments (e.g. testis, Hodgkin's lymphoma, or lymphocytic leukemias) contributed to the reduction of cancer mortality.

In the elderly the behavior of some cancers may become more aggressive (e.g., acute myeloid leukemia, lymphoma and ovarian cancer) or more indolent (e.g., breast and lung cancer) than in the adult age groups $[7,8]$. From this view point, the assessment of long term trends of cancer mortality offers specific clues about the introduction of early diagnosis modalities, the development of new treatment protocols, and competing causes of mortality (e.g., cardiovascular and neurologic disorders). A topic that has been poorly investigated in Italy $[7,8]$.

In the very elderly ( $\geq 85$ years), the identification of the precise cause of death is potentially complicated by a number of common life-threatening comorbidities (i.e. hypertension, chronic obstructive pulmonary diseases, or diabetes). Thus, in order to reach meaningful conclusions, analysis was restricted to the elderly.

We took advantage of the availability of computerized death certificates recorded in Italy over the 1970-2008 period to describe trends in cancer mortality among the elderly aged 65-84 years.

\section{Methods}

Information regarding the underlying cause of death for the period 1970-2008 was extracted from the database available on electronic support from the Italian National Institute of Statistics (ISTAT) [4]. Between 1970 and 2008, three different revisions of the International Classification of Disease (ICD) were used to code the underlying cause of death: the 8th revision from 1970 to 1979 [9]; the 9th revision from 1980 to 2002 [10]; and the 10th revision since 2003 [11]. To improve validity and comparability of some cancer sites/types throughout subsequent classifications, we pooled together all oral cavity and pharynx neoplasms, all intestinal sites, including rectum, all non-Hodgkin's lymphomas, and all leukemias. Deaths were recorded according to the ICD-10 as: all causes of death (ICD10: A00-Y99), all malignant and benign cancers (ICD-10: C00-D48), lip, oral cavity and pharynx (ICD10: C00-C14), esophagus (ICD-10: C15), stomach (ICD-10: C16), intestines, mainly colon and rectum (ICD-10:C18-C21), liver (ICD-10:C22.0, C22.2, C22.3, C22.4, and C22.7), pancreas (ICD-10: C25), larynx (ICD-10: C32), lung (ICD-10:C33-C34), cutaneous melanoma (ICD-10:C43), prostate (ICD-10: C61), breast (ICD10: C50), ovary (ICD-10:C56), bladder (ICD-10: C67), kidney and other urinary sites (ICD-10: C64-C66, C68), all leukemia (ICD10: C91-C95), Hodgkin's lymphoma (ICD10:C81) and non-Hodgkin's lymphomas (ICD-10:
C82-C85, C96). Resident population by sex, age, and calendar year was abstracted from the ISTAT database [12].

Data were grouped into quinquennia from 1970-74 to 1995-99, and into two shorter periods (2000-2003 and 2006-2008), because the computerization of death certificates for the years 2004 and 2005 had not been completed at the time of data analysis. Age-standardized mortality rates per 100,000 (to the world standard population [13]) were calculated in both sexes by grouped periods and annually between 1995 and 2008 according to the underlying cause of death. Rates and their corresponding standard errors were calculated using SAS 9.20 (SAS Institute Inc., Cary, NC).

The computation of annual percent change (APC) $[14,15]$ of mortality rates was restricted to the 19952008 period to specifically quantify the recent impact of cancer mortality on the elderly and on the middle aged (35-64 years) populations. APCs were estimated by fitting a linear regression line to the natural logarithm of annual mortality rates using calendar year as a regressor variable. This calculation assumes that the mortality rates changed at a constant rate over the entire calendar-year interval examined, and the validity of this assumption was checked by merely examining plotted curves. Statistical significance was assessed at $\mathrm{p}<0.05$.

\section{Results}

The number of cancer deaths and the proportion of deaths caused by cancer nearly doubled during the study period among the Italian elderly population (Table 1). In particular, the proportion increased, in men, from $21.5 \%$ in 1970-74 (31,400 deaths per year from any cancer) to $39.8 \%$ in $2006-08$ (63,000 deaths/year), and from $16.8 \%$ (24,000 deaths/year) to $32.7 \%$ (42,000 deaths/year) in women. In 2006-2008, half of overall cancer mortality in the elderly was explained, in both sexes, by few leading cancers, namely: lung (27.9\%); intestines (10.3\%); prostate $(7.6 \%)$ and stomach $(6.3 \%)$ in men, and breast (13.8\%); intestines (11.8\%); lung (10.7\%); pancreas (7.5\%) and stomach $(5.8 \%)$ in elderly women (Table 1$)$.

During the study period, overall cancer mortality rates peaked during the quinquennia 1985-89 and 1990-94 in both sexes and declined thereafter (Table 2 and Figure 1). In elderly men, rates increased from $1,306 / 100,000$ in 1970-74 to nearly 1,500 during the quinquennia 1985-89 and 1990-94, and then dropped to 1,212 in 2006-08. In elderly women, the rates increased from $671 / 100,000$ in 1970-74 to nearly 680 during the quinquennia 1985-89 and 1990-94, and then dropped to 586 in 2006-08. Between 1995-2008, APC decreased by $-1.6 \% /$ year $(95 \%$ CI: $-1.8 ;-1.4)$ in men, and by $-0.9 \% /$ year $(95 \% \mathrm{CI}:-1.0 ;-0.7)$ in women. A large variability in cancer trends was registered according to sex, period and site/type. 
Table 1 Number of deaths of selected cancers by sex according to 1970-74 and 2006-08 periods among elderly (65-84 years) population; Italy 1970-2008

Period

\begin{tabular}{|c|c|c|c|c|}
\hline & \multirow{2}{*}{\multicolumn{2}{|c|}{$1970-74$}} & \multirow{2}{*}{\multicolumn{2}{|c|}{ 2006-08 }} \\
\hline & & & & \\
\hline & $\begin{array}{l}\text { Mean number of } \\
\text { deaths per year in } \\
65-84 \text { age group }\end{array}$ & $\begin{array}{c}\% \text { on all: deaths }{ }^{+}, \\
\text {cancers }^{\circ}\end{array}$ & $\begin{array}{l}\text { Mean number of } \\
\text { deaths per year in } \\
65-84 \text { age group }\end{array}$ & $\begin{array}{c}\% \text { on all: deaths } \\
\text { cancers }^{\circ}\end{array}$ \\
\hline \multicolumn{5}{|l|}{ Men } \\
\hline All causes of death & 146502 & - & 158647 & - \\
\hline All cancers, benign and malignant & 31435 & $21.5+$ & 63160 & $39.8+$ \\
\hline Lip, oral cavity and pharynx & 1010 & $3.2^{\circ}$ & 1001 & $1.6^{\circ}$ \\
\hline Esophagus & 887 & $2.8^{\circ}$ & 783 & $1.2^{\circ}$ \\
\hline Stomach & 6052 & $19.3^{\circ}$ & 3981 & $6.3^{\circ}$ \\
\hline Intestines, mainly colon \& rectum & 3400 & $10.8^{\circ}$ & 6498 & $10.3^{\circ}$ \\
\hline Liver & 541 & $1.7^{\circ}$ & 1757 & $2.8^{\circ}$ \\
\hline Pancreas & 934 & $3.0^{\circ}$ & 3030 & $4.8^{\circ}$ \\
\hline Larynx & 1045 & $3.3^{\circ}$ & 944 & $1.5^{\circ}$ \\
\hline Lung & 6551 & $20.8^{\circ}$ & 17639 & $27.9^{\circ}$ \\
\hline Cutaneous melanoma & 54 & $0.2^{\circ}$ & 477 & $0.8^{\circ}$ \\
\hline Prostate & 2898 & $9.2^{\circ}$ & 4824 & $7.6^{\circ}$ \\
\hline Bladder & 1499 & $4.8^{\circ}$ & 2924 & $4.6^{\circ}$ \\
\hline Kidney & 366 & $1.2^{\circ}$ & 1539 & $2.4^{\circ}$ \\
\hline Leukemia & 787 & $2.5^{\circ}$ & 2015 & $3.2^{\circ}$ \\
\hline Hodgkin lymphoma & 159 & $0.5^{\circ}$ & 113 & $0.2^{\circ}$ \\
\hline Non-Hodgkin lymphoma & 293 & $0.9^{\circ}$ & 1497 & $2.4^{\circ}$ \\
\hline \multicolumn{5}{|l|}{ Women } \\
\hline All causes of death & 142098 & - & 127897 & - \\
\hline All cancers, benign and malignant & 23911 & $16.8+$ & 41839 & $32.7+$ \\
\hline Lip, oral cavity and pharynx & 214 & $0.9^{\circ}$ & 384 & $0.9^{\circ}$ \\
\hline Esophagus & 253 & $1.1^{\circ}$ & 245 & $0.6^{\circ}$ \\
\hline Stomach & 4694 & $19.6^{\circ}$ & 2434 & $5.8^{\circ}$ \\
\hline Intestines, mainly colon and rectum & 3478 & $14.5^{\circ}$ & 4935 & $11.8^{\circ}$ \\
\hline Liver & 495 & $2.1^{\circ}$ & 448 & $1.9^{\circ}$ \\
\hline Pancreas & 856 & $3.6^{\circ}$ & 3138 & $7.5^{\circ}$ \\
\hline Larynx & 65 & $0.3^{\circ}$ & 79 & $0.2^{\circ}$ \\
\hline Lung & 1144 & $4.8^{\circ}$ & 4465 & $10.7^{\circ}$ \\
\hline Cutaneous melanoma & 54 & $0.2^{\circ}$ & 321 & $0.8^{\circ}$ \\
\hline Breast & 2842 & $11.9^{\circ}$ & 5781 & $13.8^{\circ}$ \\
\hline Ovary & 558 & $2.3^{\circ}$ & 1764 & $4.2^{\circ}$ \\
\hline Bladder & 415 & $1.7^{\circ}$ & 638 & $1.5^{\circ}$ \\
\hline Kidney & 255 & $1.1^{\circ}$ & 762 & $1.8^{\circ}$ \\
\hline Leukemia & 634 & $2.7^{\circ}$ & 1487 & $3.6^{\circ}$ \\
\hline Hodgkin lymphoma & 125 & $0.5^{\circ}$ & 97 & $0.2^{\circ}$ \\
\hline Non-Hodgkin lymphoma & 237 & $1.0^{\circ}$ & 1384 & $3.3^{\circ}$ \\
\hline
\end{tabular}

In men, esophagus, larynx, and stomach cancer mortality rates decreased continuously throughout the whole period. Hodgkin lymphoma mortality declined after 1975-79. Cancers of the lip, oral cavity and pharynx, bladder, and prostate declined after 1985-89. Declines after 1990-94 were recorded for cancers of the liver, lung, and kidney (which leveled-off from 2000-03). After 1995-99 declines were observed for 
Table 2 Time trends of selected cancer death rates among elderly and middle aged populations; Italy, 1970-2008

Cause of death

or groups of diseases
Age Standardized Rates (World population)

in elderly (65-84 years) $\times 100,000$
Annual Percent Change

from 1995 to 2008
Period

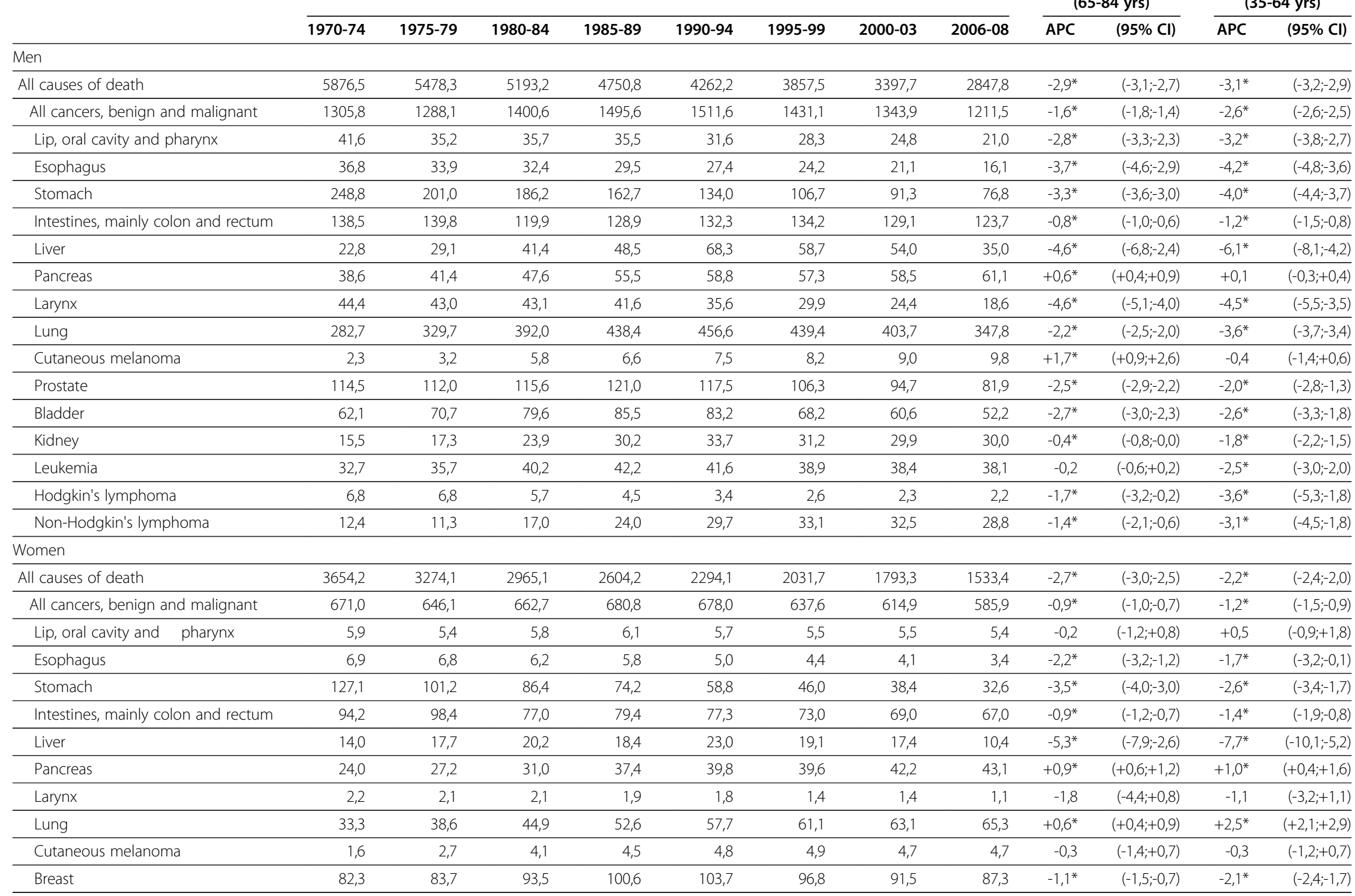


Table 2 Time trends of selected cancer death rates among elderly and middle aged populations; Italy, 1970-2008 (Continued)

\begin{tabular}{lrrrrrrrrrrrrrr}
\hline Ovary & 16,8 & 18,0 & 22,2 & 28,1 & 29,8 & 27,4 & 26,9 & 27,2 & 0,0 & $(-0,6 ;+0,6)$ & $-0,8^{*}$ & $(-1,5 ;-0,2)$ \\
\hline Bladder & 11,3 & 12,4 & 12,9 & 12,4 & 12,0 & 9,4 & 8,7 & 7,9 & $-1,9^{*}$ & $(-2,5 ;-1,2)$ & $-1,2$ & $(-3,2 ;+0,8)$ \\
\hline Kidney & 7,5 & 8,2 & 9,8 & 11,6 & 12,0 & 11,3 & 11,0 & 10,4 & $-0,9^{*}$ & $(-1,5 ;-0,3)$ & $-2,4^{*}$ & $(-3,5 ;-1,4)$ \\
\hline Leukemia & 18,3 & 20,0 & 21,8 & 21,4 & 22,6 & 21,0 & 20,7 & 20,3 & $-0,4$ & $(-0,9 ;+0,2)$ & $-3,0^{*}$ & $(-3,9 ;-2,1)$ \\
\hline Hodgkin's lymphoma & 3,6 & 4,0 & 3,3 & 2,5 & 2,1 & 1,4 & 1,3 & 1,3 & $-0,8$ & $(-2,4 ;+0,9)$ & $-2,9^{*}$ & $(-5,7 ;-0,1)$ \\
\hline Non-Hodgkin's lymphoma & 6,9 & 6,8 & 10,0 & 14,7 & 19,7 & 22,6 & 22,4 & 18,5 & $-1,7^{*}$ & $(-2,7 ;-0,7)$ & $-3,8^{*}$ & $(-4,9 ;-2,7)$ \\
\hline
\end{tabular}

*Significantly different from 0 ( $p<0.05)$; APC: Average Percent Change. 


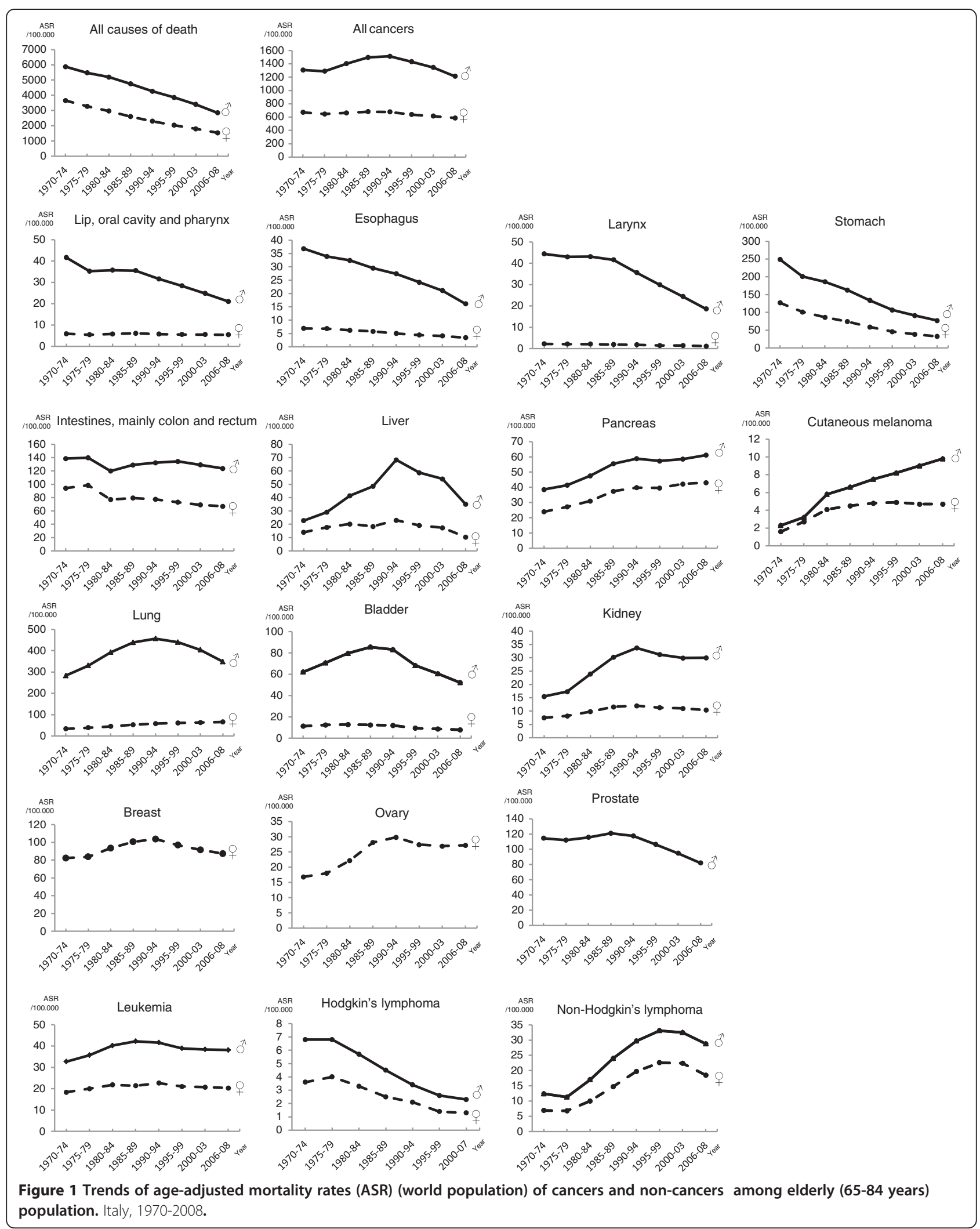


cancer of the intestines, and non-Hodgkin lymphomas. Conversely, increased trends were observed for cancer of the pancreas and for cutaneous melanoma.

In women, esophagus, larynx, and stomach cancers declined continuously throughout the entire period, while intestines cancer, and Hodgkin lymphoma declined after 1975-79. Lip, oral cavity and pharynx cancers decreased after 1985-84 (reaching a plateau from 1995-99 onwards). Cancers that declined after 1990-94 were liver, breast, ovary (that leveled-off since 1995-99), bladder, kidney, and leukemia (stable since 2000-03). Non-Hodgkin lymphoma declined after 199599. By contrast, lung and pancreatic cancer mortality rates increased throughout the whole period examined. Cutaneous melanoma increased up to 1995-99 and leveled-off thereafter.

Furthermore, between 1995 and 2008 in the elderly, cancer rates showed several statistically significant negative APCs. In elderly men the highest decreases were displayed by cancers of the liver, and larynx $(\mathrm{APC}=$ $-4.6 \% /$ year), followed by cancer of the esophagus $(\mathrm{APC}=$ $-3.7 \% /$ year), stomach (APC $=-3.3 \% /$ year), lip, oral cavity and pharynx $(\mathrm{APC}=-2.8 \% /$ year $)$, bladder $(\mathrm{APC}=-2.7 \%$ / year), prostate $(\mathrm{APC}=-2.5 \% /$ year $)$, lung $(\mathrm{APC}=-2.2 \%$ / year), Hodgkin lymphomas $(\mathrm{APC}=-1.7 \% /$ year $)$, nonHodgkin lymphomas (APC $=-1.4 \% /$ year $)$, and intestines $(\mathrm{APC}=-0.8 \% /$ year $)$. Increases were seen for pancreas carcinoma $(\mathrm{APC}=+0.6 \% /$ year $)$, cutaneous melanoma $(\mathrm{APC}=+1.7 \% /$ year $)$, and kidney cancer that leveled-off from 2000-03. In women the largest decreases were observed by cancer of the liver (APC $=-5.3 \% /$ year) followed by cancer of the stomach $(\mathrm{APC}=-3.5 \% /$ year $)$, esophagus $(\mathrm{APC}=-2.2 \% /$ year$)$, bladder $\quad(\mathrm{APC}=-1.9 \%$ / year), larynx $(\mathrm{APC}=-1.8 \% /$ year $)$, non-Hodgkin lymphoma $(\mathrm{APC}=-1.7 \% /$ year $)$, breast $(\mathrm{APC}=-1.1 \% /$ year $)$, and kidney $(\mathrm{APC}=-0.9 \% /$ year $)$. Increases were displayed by cancer of the pancreas ( $\mathrm{APC}=+0.9 \% /$ year) and lung (APC $=+0.6 \% /$ year). Lip, oral cavity and pharynx cancers, ovary, melanoma, Hodgkin lymphomas and leukemia showed stable trends.

By comparison with the other age groups, between 1995 and 2008 overall cancer mortality rates declined for people aged $<40$ years $(-1.7 \%$ /year in men and $-1.8 \% /$ year in women), and for middle aged (35-64 years) people $(-2.6 \% /$ year in men and $-1.2 \%$ /year in women) (Table 2 ) while rates in the very elderly ( $\geq 85$ years) people increased in men $(+0.6 \% /$ year $)$ and decreased in women $(-0.2 \% /$ year) (not shown). As compared to the elderly, middle aged men displayed higher decreases in cancer mortality for lung, kidney, and leukemia, while middle aged women showed higher decreases in cancer mortality for breast, leukemia and non-Hodgkin's lymphomas. Conversely, middle aged women presented higher increases of lung cancer mortality than elderly women. The other APCs were similar in elderly and middle aged people.

\section{Discussion}

Our investigation of cancer mortality trends among the Italian elderly population across approximately four decades (1970-2008) showed an increase of the absolute number of cancer deaths, but decreases in cancer mortality rates for several sites. These decreases reflected those observed in four leading cancers in men (stomach, bladder, prostate, and lung) and three leading cancers in women (stomach, bladder, and breast). Exceptions to these favorable trends were the increased mortality rates for lung cancer in women, cutaneous melanoma in men, and pancreatic cancer in both sexes. However, the general favorable trends of the majority of cancers were still modest over the same period of time when compared to the higher drops in mortality observed for diseases of the circulatory system and respiratory system, (Additional file 1: Table S1). As compared to middle aged people, the elderly displayed lower decreases for leukemia, lung and kidney cancers in men and for leukemia, non-Hodgkin's lymphomas, and breast cancer. By contrast, middle aged women presented higher increases of lung cancer mortality than elderly women.

The downward trends observed for cancer mortality rates among Italian elderly between 1995 and 2008 were generally consistent with those reported over a comparable period of time in Japan (1998-2007), Canada (19952004), United States (1996-2005), and England, and Wales (1997-2006) [16].

Several reasons related to large scale changes in exposure to risk factors and to improvements in diagnosis and treatment may explain these trends. For instance, decreases in prevalence of smoking in men caused the decline of lung cancer incidence and mortality, and partially a decline in bladder, kidney, and larynx cancer $[17,18]$. The time shift observed for bladder cancer indicates, in addition to smoking, a reduction in exposures to occupational carcinogens [18]. Moreover, the decrease and subsequent plateau reached by kidney cancer indicates that obesity and/or hypertension inhibit further drops in rates of this cancer [19]. Decreases in alcohol consumption partly explain the reductions of cancers of the lip, oral cavity and pharynx, esophagus, and larynx [20]. In men, smoking reduction hampered the drop of lip, oral cavity and pharynx, and larynx cancers in the mid-1980s [20]. Changes in viral hepatitis prevalence rather than alcohol consumption seemed to explain the drop of liver cancer, as alcohol related cancers declined since the 1970s [21]. However, the complexity in differentiating primary and secondary liver cancer in death certificates requires some caution in the interpretation of 
these results. Reduction of stomach cancer mortality is generally attributed to a healthier diet, improved preservation of foods, and reduced prevalence of Helicobacter pylori [22]. Advancements in screening and early diagnosis and, consequently, effective therapy can chiefly explain the peak of breast cancer observed in the early 1990s. Ovarian cancer displayed a parallel peak to the one of breast cancer that leveled-off since the mid-1990s, a pattern that may be linked to delayed diagnoses [23]. Progresses in surgical techniques, adjuvant therapy, and declines in exposure to risk factors are likely explanations for the slight decrease in intestinal cancer over time [24]. Population-based screening for colorectal cancers was not widely available in Italy at the time of the study; therefore, it could not influence these trends, while drops in the mortality for prostate cancer since the mid-1980s are likely due to therapy advancements.

Although evidence-based data restricted to the elderly are scanty, it is generally accepted that overall improvements in anti-cancer treatment has contributed to reduce cancer mortality also in the elderly. An example is the early adoption of transurethral resection of the prostate as well as androgen blockage and radiotherapy for patient with locally advanced disease. Moreover, declines in mortality rates for prostate cancer have been affected also by chemotherapy with Docetaxel [25].

Pancreatic cancer mortality increased since the 1970s, leveled-off in correspondence to the peak of lung cancer in mid-1990s, to increase thereafter, maybe, in association with the increase of diabetes prevalence [26]. Cutaneous melanoma is directly linked to excessive sun exposure. The level-off in women, but not in men, indicates changes in exposure rather than selective therapy advancements [27]. Finally, therapy advancements were associated to the peak of Hodgkin lymphoma mortality in the mid-1970s. Compared with young patients, the elderly are at an advanced stage, have lower performance status, and generally have a more aggressive biology of the disease and poor outcome [28]. The decrease in mortality for non-Hodgkin lymphoma at the end of 1990s is attributable to improved therapies like the introduction of Rituximab [29]. Death certificates do not allow the distinction of various types of leukemia; therefore, the observed trends are difficult to interpret.

Cancer death certifications data have some limitations in accuracy and completeness that should be made clear. Firstly, the primary site of particular cancers is not always ascertained by means of death certificates. In accordance with such drawbacks, some sites were pooled together: lip, oral cavity and pharynx, colon and rectal cancers, non-Hodgkin lymphomas, and leukemias. Moreover, before ICD-10 use, primary liver cancer was not always distinguishable from metastases of other cancers. These limitations were taken into account in the interpretation of time trends. Secondly, cancer and comorbidities are extremely common in elderly people and the percentage of histologically confirmed cancers is generally lower among them than in younger age groups. Thus, the identification of the true underlying cause of death may be difficult, with occurrence of both false positive and false negative errors. Between 1970 and 2008, three different ICD coding rules were used to indicate the underlying cause of death and the criteria for malignancy. The changes in the classification of tumors were overcome by recoding diagnoses according to ICD10. The overall increased precision should have inflated mortality rates over time; however, in this study, the main groups of diseases showed declines. Thirdly, the accuracy of mortality data derived from death certificates depends from coding practices. In Italy, the coding of the cause of deaths is conducted at national level according to strict guidelines, also by means of an automated system, thus limiting the possibility of differential practices influencing death certification procedures.

Some points can be drawn from the trends of cancer mortality in the elderly in the last four decades. Firstly, preventive strategies, smoking in the first place, apply well to the elderly. Cancer prevention must be further promoted and targeted to this specific population. Secondly, the elderly generally present high prevalence of slowly growing cancers, a life expectancy, and a quality of life compatible with a benefit from screening or early diagnosis However, they are frequently excluded from these benefits. Thirdly, the elderly may be unable to access care that is otherwise considered standard for an adult population.

\section{Conclusions}

In conclusion our study, focused on the whole Italian elderly population, showed favorable trends in mortality rates from 1970 to 2008 for many cancers, although in absolute terms, the number of cancer deaths doubled. However, further efforts in prevention, applicability of screenings, and access to care need to be reconsidered as the Italian population ages.

\section{Additional file}

Additional file 1: Table 3. Time trends of main causes of death among elderly and middle aged populations; Italy, 1970-2008.

\section{Competing interests}

The authors declare that they have no competing interests.

\section{Authors' contributions}

EB and DS performed all analyses and produced the primary manuscript:

SB and MP participated in the acquisition of data; All authors read, participated in discussions of appropriate groups for analysis and

interpretation, and approved the final manuscript. 


\section{Acknowledgements}

The authors wish to thank Mrs L. Mei for editorial assistance and M. Volpato for study coordination.

\section{Author details}

'Unit of Epidemiology and Biostatistics, Centro di Riferimento Oncologico, IRCCS, via Franco Gallini 2, 33081 Aviano, PN, Italy. ²Division of Medical Oncology A, Centro di Riferimento Oncologico, IRCCS, Aviano, Italy. ${ }^{3}$ Direzione Centrale per le Statistiche e le Indagini Sulle Istituzioni Sociali, Servizio Sanità e Assistenza, National Institute of Statistics, Rome, Italy. ${ }^{4}$ Direzione Scientifica, Centro di Riferimento Oncologico, IRCCS, Aviano, Italy. 5Department of Medical Oncology, Centro di Riferimento Oncologico, IRCCS Aviano, Italy.

Received: 17 April 2012 Accepted: 25 September 2012 Published: 2 October 2012

\section{References}

1. Peto R, Doll R: There is no such thing as aging. BMJ 1997, 315:1030-1032.

2. Franceschi S, LA Vecchia C: Cancer epidemiology in the elderly. Critical Rev Oncol Hematol 2001, 39:219-226.

3. Armitage $P$, Doll $R$ : The age distribution of cancer and a multi-stage theory of carcinogenesis. Br J Cancer 1954, 8:1-12

4. Italian National Institute of Statistics. http://demo.istat.it; http//www.istat.it.

5. La Vecchia C, Bosetti C, Lucchini F, Bertuccio P, Negri E, Boyle P, Levi F: Cancer mortality in Europe, 2000-2004, and an overview of trends since 1975. Ann Oncol 2010, 21:1323-1360.

6. Arfè A, Malvezzi M, Bertuccio P, Decarli A, La Vecchia C, Negri E: Cancer mortality trend analysis in Italy, 1970-2007. Eur J Cancer Prev 2011, 20:364-374.

7. Levi F, La Vecchia C, Lucchini F, Negri E: Worldwide trends in cancer mortality in the elderly, 1955-1992. Eur J Cancer 1996, 32A:652-672.

8. Levi F, Lucchini F, Negri E, Boyle P, La Vecchia C: Changed trends of cancer mortality in the elderly. Ann Oncol 2001, 12:1467-1477.

9. World Health Organization: International classification of disease, 8th revision. Geneva: World Health Organization; 1967.

10. World Health Organization: International classification of disease, 9th revision. Geneva: World Health Organization; 1977.

11. World Health Organization: International statistical classification of disease and related health problems, 10th revision. Geneva: World Health Organization; 1992.

12. Italian National Institute of Statistics: Available upon request. at: http://www.istat.it.

13. Waterhouse J, Muir C, Correa P, Powell J: Cancer Incidence in Five Continents. Lyon: IARC Sci Publ; 1976:456

14. Kim HJ, Fay MP, Feuer EJ, Midthune DN: Permutation tests for joinpoint regression with applications to cancer rates. Stat Med 2000, 19:335-351. correction: 2001, 20:655.

15. National Cancer Institute: Joinpoint Regression Program. version 343rd edition; 2010. Available at: http://srab.cancer.gov/jointpoint

16. Yang L, Fujimoto J, Qiu D, Sakamoto N: Trends in cancer mortality in the elderly in Japan, 1970-2007. Ann Oncol 2010, 21:389-396.

17. Doll R, Peto R, Boreham J, Sutherland I: Mortality from cancer in relation to smoking: 50 years observations on British doctors. $\mathrm{Br} J$ Cancer 2005, 92:426-429

18. Ferlay J, Randi G, Bosetti C, Levi F, Negri E, Boyle P, La Vecchia C: Declining mortality from bladder cancer in Europe. BJU Int 2008, 101:11-19.

19. Brennan P, Van der Hel O, Moore LE, Zaridze D, Matveev V, Holcatova I, Janout V, Kollarova H, Foretova L, Szeszenia-Dabrowska N, Mates D, Rothman N, Boffetta P: Tobacco smoking, body mass index, hypertension, and kidney cancer risk in central and eastern Europe. Br J Cancer 2008, 99:1912-1915.

20. Fernandez L, Lubin JH, Muscat J, Gaudet MM, Olshan AF, Curado MP, Dal Maso L, Wunsch-Filho V, Sturgis EM, Szeszenia-Dabrowska N, Casterlsague X, Zhang ZF, Smith E, Matos E, Franceschi S, Fabianova E, Rudnai P, Purdue MP, Mates D, Wei Q, Herrero R, Kelsey K, Morgenstern H, Shangina O, Koifman S, Lissowska J, Levi F, Daudt AW, Neto JE, Chen C, Lazarus P. Winn DM, Schwartz SM, Boffetta P, Brennan P, Menezes A, La Vecchia C, McClean M, Talamini R, Rajkumar T, Hayes RB, Hashibe M: An examination of male and female odds ratios by $\mathrm{BMI}$, cigarette smoking, and alcohol consumption for cancers of the oral cavity, pharynx, and larynx in pooled data from 15 case-control studies Cancer Causes Control 2011, 22:1217-1231.

21. Bosetti C, Levi F, Boffetta P, Lucchini F, Negri E, La Vecchia C: Trends in mortality from hepatocellular carcinoma in Europe, 1980-2004. Hepatology 2008, 48:137-145

22. Pelucchi C, Tramacere I, Bertuccio P, Tavani A, Negri E, La Vecchia C: Dietary intake of selected micronutrients and gastric cancer risk: an Italian case-control study. Ann Oncol 2009, 20:160-165.

23. Garattini S, La Vecchia C: Perspectives in cancer chemotherapy. Eur J Cancer 2001, 37(Suppl 8):S128-S147.

24. Rougier P, Mitry E: Epidemiology, treatment and chemoprevention in colorectal cancer. Ann Oncol 2003, 14(Suppl 2):ii3-ii5.

25. Tannock IF, de Wit R, Berry WR, Horti J, Pluzanska A, Chi KN, Oudard S, Théodore C, James ND, Turesson I, Rosenthal MA, Eisenberger MA: TAX 327 Investigators: Docetaxel plus prednisone or mitoxantrone plus prednisone for advanced prostate cancer. N Engl J Med 2004, 351:1502-1512.

26. Boffetta P, La Vecchia C: Neoplasms. In Oxford Textbook of Public Health. 5th edition. Edited by Detels R, Beaglehole R, Lansang MA, Martin Gulliford M. New York: Oxford University Press; 2009:997-1020.

27. Naldi L, Altieri A, Imberti GL, Gallus S, Bosetti C, La Vecchia C, Oncology Study Group of the Italian Group of Epidemiologic Research in Dermatology: Sun exposure, phenotypic characteristics, and cutaneous malignant melanoma. An analysis according to different clinico-pathological variants and anatomic locations (Italy). Cancer Causes Control 2005, 16:893-899.

28. Carbone A, Spina M, Gloghini A, Tirelli U: Classical Hodgkin' Lymphoma arising in different host's conditions: pathobiology parameters, therapeutic options and outcome. Am J Hematol 2011, 86:170-179.

29. Coiffier B, Lepage E, Briere J, Herbrecht R, Tilly H, Bouabdallah R, Morel P, Van Den Neste E, Salles G, Gaulard P, Reyes F, Ledelin P, Gisselbrecht C: CHOP chemotherapy plus rituximab compared with $\mathrm{rCHOP}$ alone in elderly patients with diffuse large B-cell lymphoma. N Engl J Med 2002, 346:235-42

doi:10.1186/1471-2407-12-443

Cite this article as: Bidoli et al:: Time trends of cancer mortality among elderly in Italy, 1970-2008: an observational study. BMC Cancer 2012 $12 \cdot 443$

\section{Submit your next manuscript to BioMed Central and take full advantage of:}

- Convenient online submission

- Thorough peer review

- No space constraints or color figure charges

- Immediate publication on acceptance

- Inclusion in PubMed, CAS, Scopus and Google Scholar

- Research which is freely available for redistribution 